\title{
FE MODELLING OF A COUPLED THERMAL-ELASTIC-PLASTIC ANALYSIS IN A RAIL-WHEEL CONTACT
}

\author{
PÉTER. T. ZWIERCZYK AND KÁROLY VÁRADI \\ Department of Machine and Product Design \\ Budapest University of Technology and Economics \\ H-1111 Budapest, Müegyetem rkp. 3., Hungary \\ z.peter@gt3.bme.hu, varadik@eik.bme.hu
}

[Received: September 7, 2015. Accepted: December 18, 2015]

Dedicated to Professor Barna Szabó on the occasion of his eightieth birthday and to Professor Imre Kozák on the occasion of his eighty-fifth birthday

\begin{abstract}
The aim of our analyses was to model the process of the thermal micro-crack development on and under a railway wheel tread, equipped only with a disk brake during an intensive braking procedure. Considering the fact that the thermal micro-crack development is a complex problem, a multistage finite element modelling technique was developed. Using the new modelling approach, the heat and the thermal stress development can be observed between the wheel and the rail using thermal and coupled thermal-elastic-plastic FE simulations.
\end{abstract}

Keywords: Micro-crack development, heat and thermal stresses

\section{INTRODUCTION}

During intensive wheel-braking of the railway vehicles it appears that the wheel slides on the rail. While the macroscopic sliding speed is restricted it is not eliminated by the WSP (Wheel Slide Protection System). Through the sliding process considerable heat

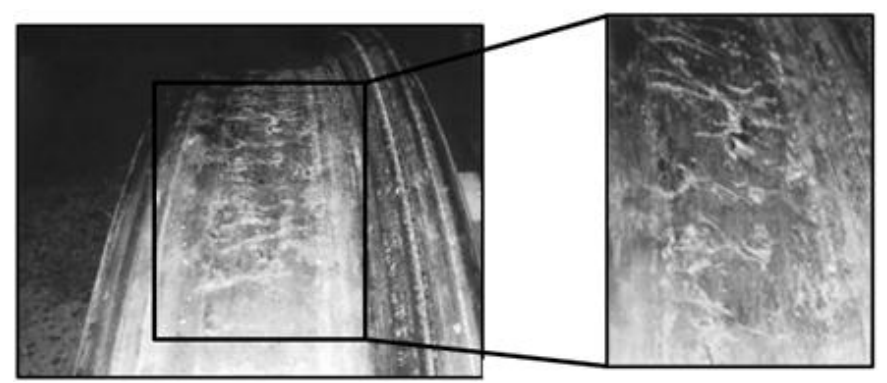

Figure 1. Highlighted thermal cracks on the surface of the wheel tread 1

\footnotetext{
${ }^{1}$ Photo courtesy of BUTE Department of Aeronautics, Naval Architecture and Railway Vehicles
} 
is generated between the connecting parts. This heat may cause micro-cracks on and under the wheel tread. These phenomena can be observed not only on vehicles equipped with brake pads but also on those with a disk brake. A great of research is focusing on the heat development between the wheel and the rail and the different defects of the railway wheels using various calculation methods. In order to analyse the contact temperature and the temperature fields of components in a relative sliding motion Knothe and Liebelt [1] used Laplace transformations combined with the method of Green's functions. They reduced the three-dimensional problem, as an approximation, to a two-dimensional one. Tanvir $[2]$ also applied the Laplace transformation method to the determine the temperature on and under the wheel tread. A new mathematical model was developed to investigate the temperature distribution, in the case of rolling contact and at different slips, between the wheel and the rail by Spiryagin et al. 3]. Their investigation involved the one- and the so-called two-point contact cases as well.

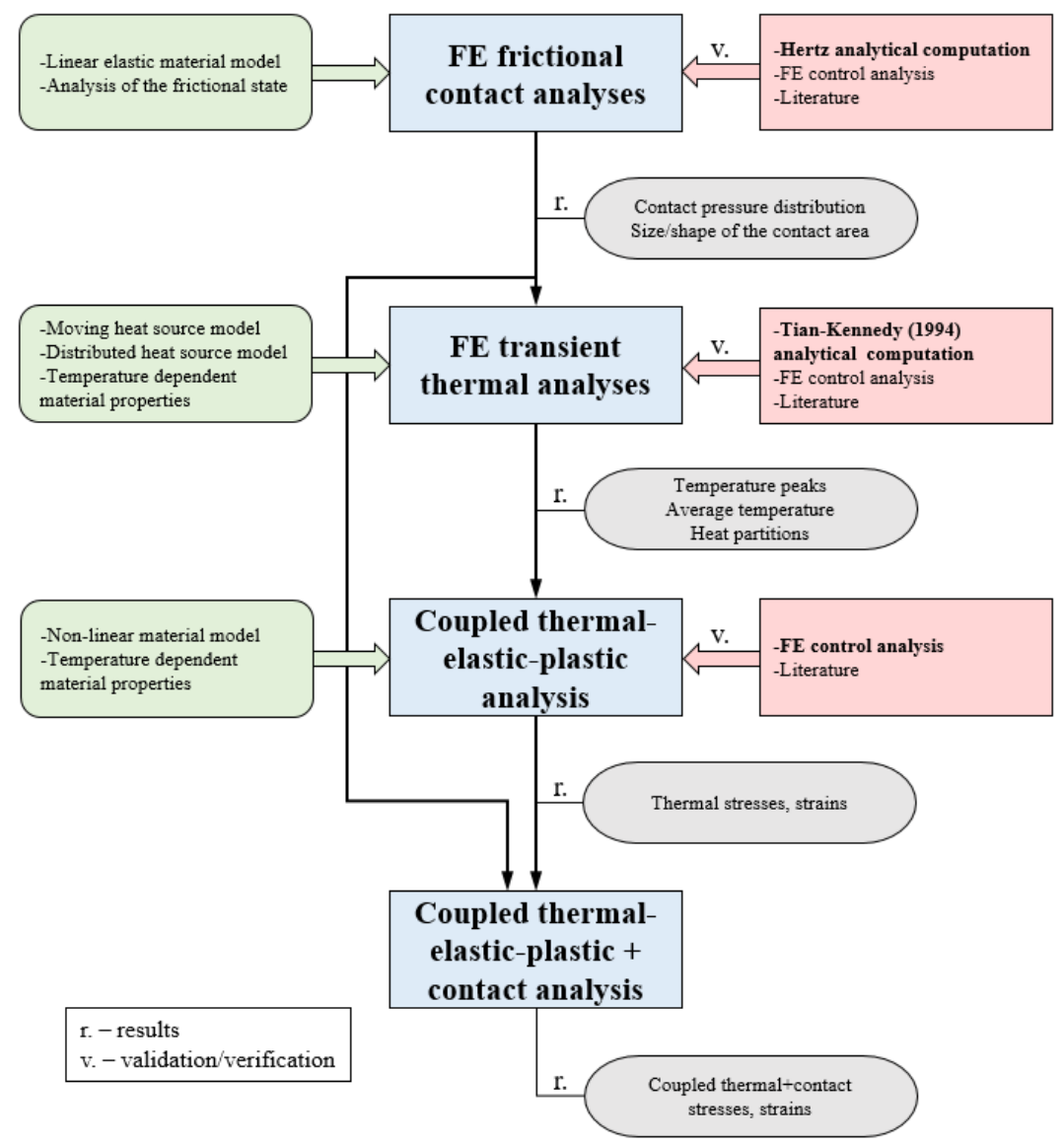

Figure 2. The schematic structure of the multistage FE modelling method 4, 5 
Beside the analytical calculation methods many authors used numerical models to analyse the temperature distribution. Gupta et al. 6 used both two- and threedimensional FE models to analyse the temperature rise and distribution on and under the tread of a locomotive wheel in the case of different combinations of creep and adhesion. Ertz and Knothe [7] computed the maximum surface temperature during rolling contact with sliding friction between the wheel and the rail with semi-analytical and numerical methods. In addition they created a comparison of the previous results. Kennedy et al. 8, to determine the temperature distribution and the heat partition between the elements in frictional contact, used a transient FE model. Furthermore, the results were compared with many analytical solutions. Sábitz and Zobory 9] as well as Sábitz and Kolonits 10 also used FEM to investigate the temperature distribution on the surface of the wheel tread.

The finite element method is also popular in the case of the examination of the stress field caused by the temperature distribution. Wu et al. [11 using two-dimensional FEM model, analysed the residual stress and strain distributions on and under a rail head in the case of different loading cases and passes with or without thermal load. Furthermore Sábitz and Zobory [12, Peng et al. [13 and Peng et al. 14] also used the finite element method to investigate the thermal stress distribution in the case of a tread braked wheel in the same cases, allowing for the so-called "rail chill" effect. The finite element method is also used as a tool to investigate wheel defects (e.g. thermal fatigue cracks, rolling contact fatigue, etc.) together with experimental investigations. Makino et al. 15 analysed shelling as a typical rolling fatigue crack with FE method and with two cylindrical specimens. Similarly Kabo 16], Ringsberg and Lindbäck [17] and Pletz et al. 18] chose FEM to examine rolling fatigue during different situations. An experimental test equipment was used by Handa et al. 19 to examine the tread thermal crack development and propagation. The analysis involved not only the wheel-rail contact but also the tread breaking process. The same test apparatus was used by Handa and Morimoto 20 to investigate the dominant factor of thermal crack development and the possible countermeasures.

In our research a multistage finite element model was developed to investigate the complete background of the thermal micro-crack development on and under a wheel tread, equipped only with a cdisk brake under an intensive braking process. For the elaboration the ANSYS Workbench V14.5 software was used.

\section{The structure of the multistage finite Element Model}

Taking into consideration that the problem under examination is so complicated, the problem has been divided into several smaller tasks with several partial FE models. The analysis of the contact and the frictional state of a wheel-rail connection and the heat and the thermal stress generation between them were examined separately. To verify the new FE modelling method and validate the results, analytical and/or numerical methods were used at each model stage. The schematic structure of our multistage FE modelling method can be seen in Figure 2 
In the first stage a frictional contact analysis was performed using a simplified segmented wheel-rail geometry. During the calculation half a model was used. In the following stages the size of the models were also modified. In the course of the thermal and the coupled analyses, a $14^{\circ}$-piece of a railway wheel with simplified geometry and a 175 -mm long rail, compliant with the UIC $60 \mathrm{E} 1$ profile standard (both also segmented) were examined (Zwierczyk and Váradi 21]).

In the different computational steps, different basic contact assumptions were used. During the computation of the contact, real-life contact conditions, an elliptical contact patch and parabolic contact pressure distribution (analytical models), caused by the bodies in contact, were taken into consideration. During the transient thermal and the coupled transient thermal-elastic-plastic analyses the previously computed elliptical contact area was considered to be rectangular with uniform pressure distribution to compute the heat source. Through the combined thermal and contact analysis the formerly described rectangular contact patch with uniform pressure distribution (due to the heat source) and a parabolic pressure distribution (obtained from the contact computation) were used (Zwierczyk [4]).

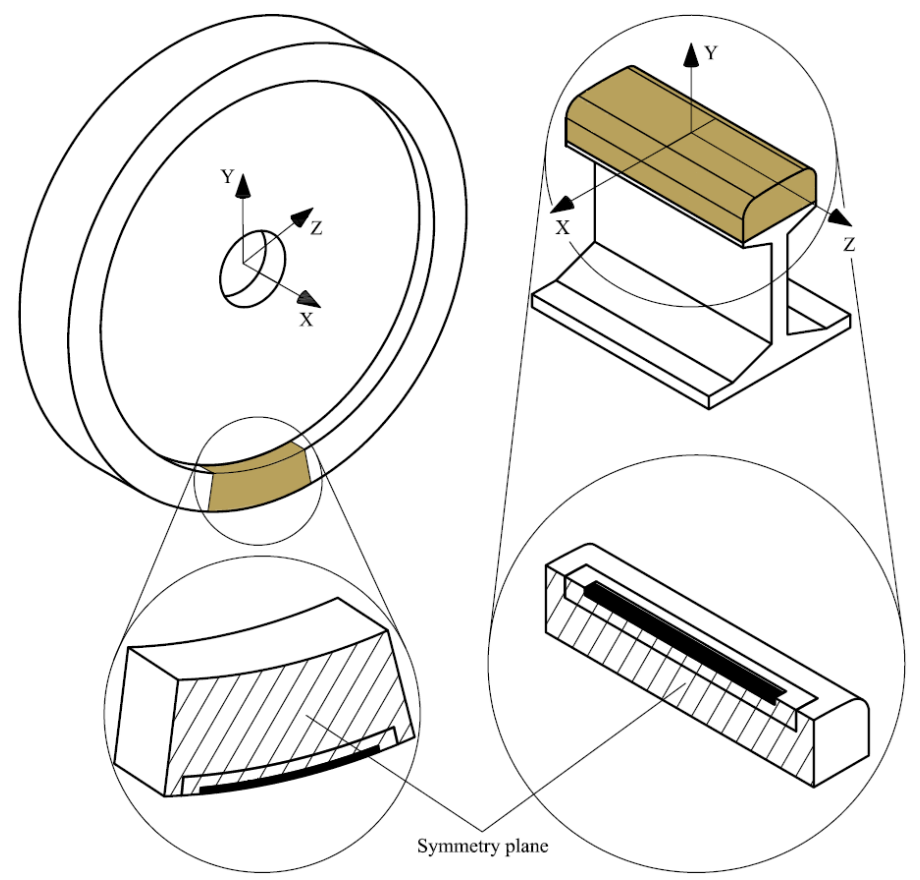

Figure 3. The initial geometries, used during the thermal and the coupled analyses 4 


\section{The RESUlts}

As a result of the frictional contact analysis the size and the shape of the contact zone, furthermore the distribution of the contact pressure, which was essential to the examination of the temperature field were determined. The significant size of the contact ellipse radiuses and the contact pressure distribution can be seen in Figure 5 . Besides, the complete slipping procedure of the wheel on the rail could also be investigated, also with the displacement of the contact patch within the contact zone (Zwierczyk and Váradi [21]). As was mentioned before, all stages were validated and/or

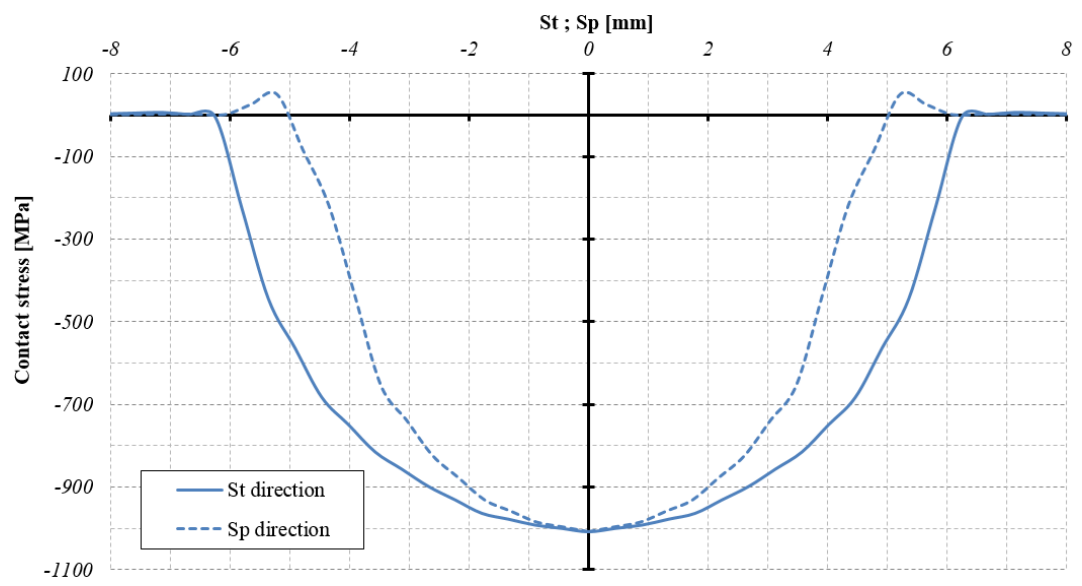

Figure 4. Contact pressure distribution and the size of the contact patch on the wheel tread (St; Sp illustrated in Figure 7) (Zwierczyk and Váradi 21 .

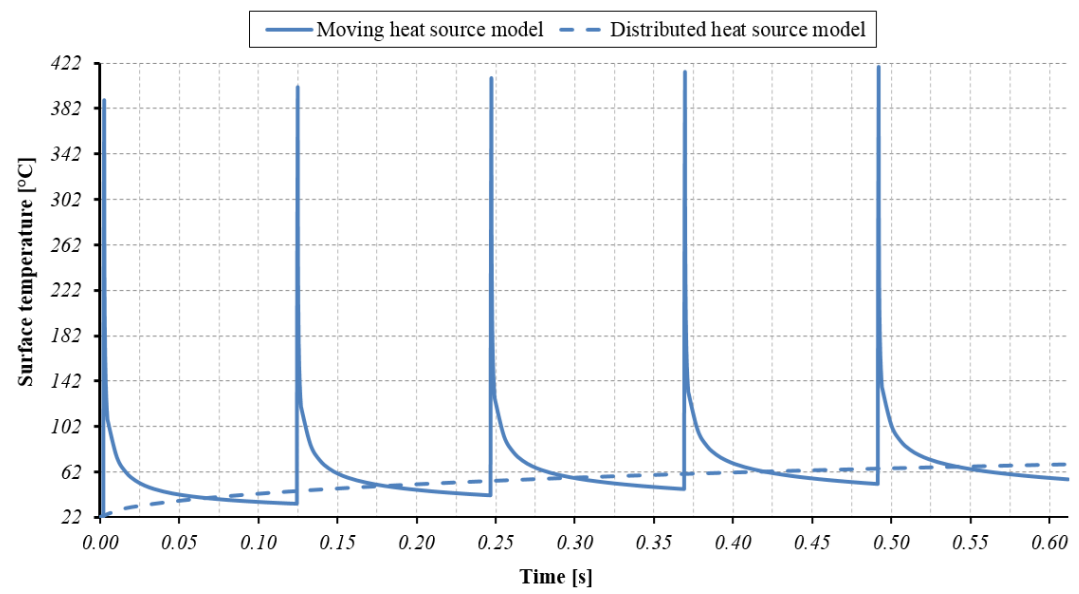

Figure 5. Temperature distribution vs. time on the wheel side during 5 revolutions (Zwierczyk 4]) 
verified with different analytical and numerical methods. In the case of the contact pressure and the size of the contact patch the Hertz theory was used to validate the results. To verify the slipping procedure and the displacements, a simplified FE control model was built (Zwierczyk [4]).

In the next step thermal analyses were performed both the wheel and the rail. Moving and distributed heat source models were built (distributed heat source models provide the "average temperature" during each revolution while moving heat source models provide information about the temperature development moment by moment in the vicinity of the contact area). As a result of these analyses the temperature distribution on and under wheel and the rail tread, furthermore the average base temperature of both of the contacting elements were determined (Zwierczyk and Váradi [22]; Zwierczyk and Váradi [23]). The heat sources were calculated using the previous contact pressure and contact patch. The thermal computation validation is based on Tian at al's [5] analytical solution, some of the results were compared with experimental data and measurement results from the literature.

For the third stage of Figure 2, a coupled thermal-elastic-plastic FE analysis was performed. With the help of this stage the stress field caused by the temperature distribution could be calculated. Figure 7 shows the von Mises stress distribution under the wheel tread. As can be seen in the figure, in the t12 time instant when heat source is just passing through the sampling line, the von Mises stress reaches the yield strength and a small plastic zone appears on and under the surface of the wheel tread. The verification of the model was elaborated by a control FE computation using submodels.

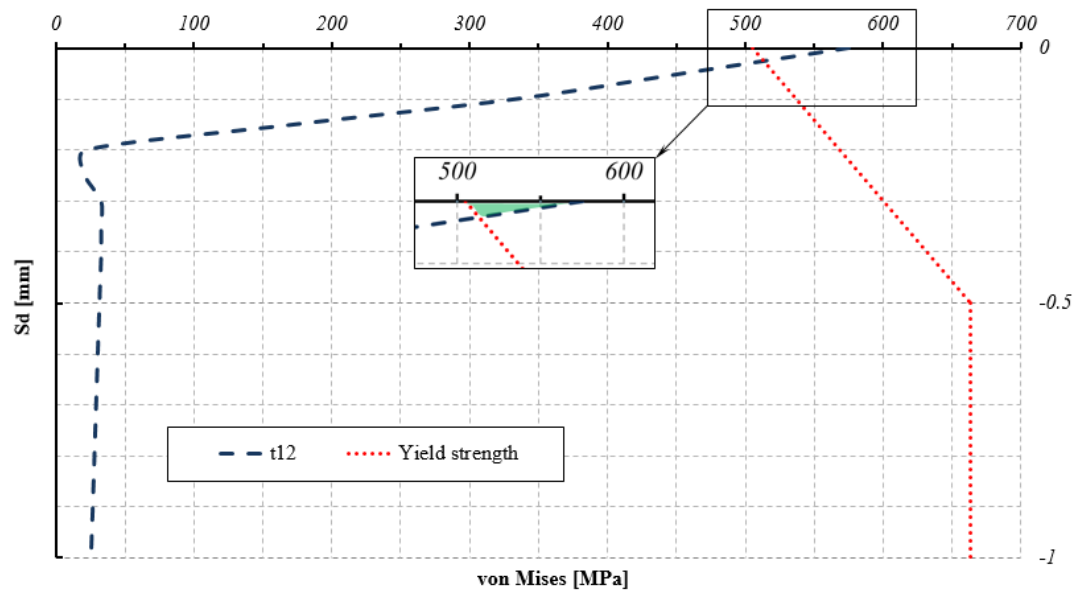

Figure 6. Distribution of von Mises stress below the tread (Sd illustrated in Figure 7) during the 1st revolution (the thin dotted line represents the yield strength as a function of temperature, t12 indicates the time instant when the von Mises stress reaches its maximum) 
In the last stage a combine contact-thermal-elastic-plastic model was elaborated using the contact pressure, calculated in the first stage. The contact pressure was applied as a load together with the heat source, as can be seen in Figure 7. Results show that because of the common effect of the thermal and mechanical load the previously computed plastic zone becomes larger and reaches deeper layers of the wheel as can be seen in Figure 8. This plastic zone may contribute to the development and the

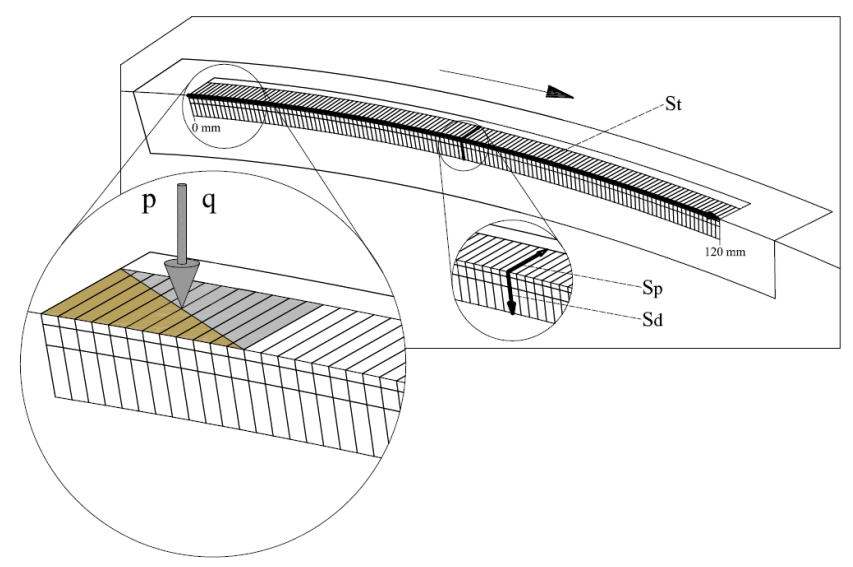

Figure 7. Method of entering heat flux and contact pressure together and the locations of the sample lines (p-contact pressure; q-heat source; sample line St according to the direction of sliding; sample line Sd in the direction of depth; sample line Sp in direction across the tread) (Zwierczyk [4])

appearance of the micro-cracks on and under the surface. The calculation method was verified with control $\mathrm{FE}$ analyses and the results were compared with measurements which are available in the literature.

\section{Conclusions}

The joint effect of contact and thermal stresses was studied with transient thermalelastic-plastic FE models. The coupled stress state caused plastic behavior in deeper layers compared to the "pure" thermal stress computations. The former stress maximums migrated from the surface to deeper layers $(0.2-0.3 \mathrm{~mm}$ under the surface). The results show that the two independent effects, i.e. the "pure" thermal stress and contact stress generation, should be analysed at the same instant because of their joint impact on micro-crack development. Our intention was to present the numerical algorithm (i.e. multistage FE modelling method), introduced in [24. The thermal aspect of the thesis was published in 22 . The coupled aspect of the transient thermal and the non-linear thermal stress analysis was published in 21. Combined contact+thermal stress results have not been published yet. Each stage of the multistage FE modelling 


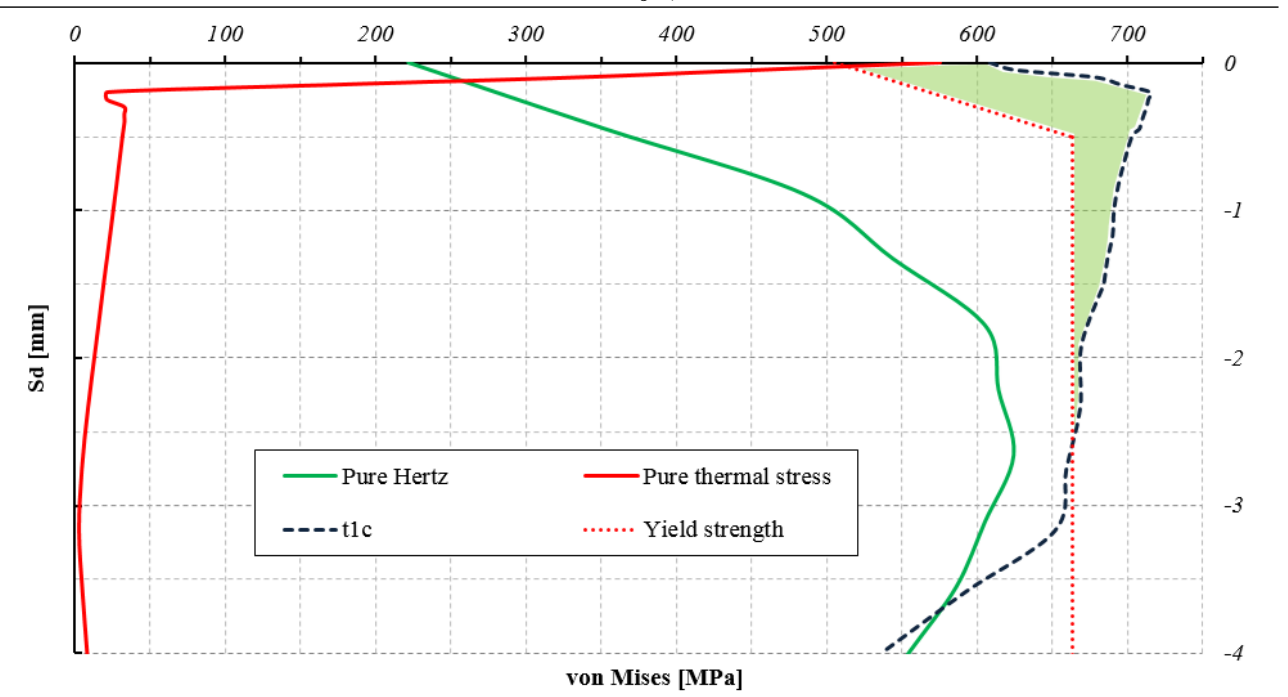

Figure 8. Distribution of von Mises stress below the tread (Sd illustrated in Figure 7) under different loading conditions during the 1st revolution (the red dotted line represents the yield strength as a function of temperature, t1c represents the common effect of the thermal and mechanical load)

method was validated and/or verified with analytical and numerical analyses, furthermore the results were confronted with the results of measurements which can be found in the literature. The results shows that with the help of these coupled models the background of this thermo-mechanical problem can be investigated using a normal personal computer.

\section{REFERENCES}

1. Knothe, K. and Liebelt, S.: Determination of temperatures for sliding contact with applications for wheel-rail systems. Wear, 189, (1995), 91-99.

2. TAnvir, M. A.: Temperature rise due to slip between wheel and rail-an analytical solution for hertzian contact. Wear, 61, (1980), 295-308.

3. Spiryagin, M., Lee, K. S., Yoo, H. H., Kashura, O., and Popov, S.: Numerical calculation of temperature in the wheel-rail flange contact and implications for lubricant choice. Wear, 268, (2010), 287-293.

4. ZWIERCZYK, P. T.: Thermal and stress analysis of a railway wheel rail rolling sliding contact. Ph.D. thesis, Budapest University of Technology and Economics, 2015.

5. Tian, X., Kennedy, J., and Francis, E.: Average flash temperatures in sliding contacts. J. Tribol., 116, (1994), 167-174.

6. Gupta, V., Hahn, G. T., Bastias, P. C., and Rubin, C. A.: Calculations of the frictional heating of a locomotive wheel attending rolling plus sliding, 4th International 
Conference on Contact Mechanics and Wear of Rail-Wheel Systems. Wear, 191, (1996), $237-241$.

7. Ertz, M. and Knothe, K.: A comparison of analytical and numerical methods for the calculation of temperatures in wheel/rail contact. Wear, 253, (2002), 498-508.

8. Kennedy, T. C., Plengsaard, C., and Harder, R. F.: Transient heat partition factor for a sliding railcar wheel. Wear, 261, (2006), 932-936.

9. SÁBitz, L. and Zobory, I.: On simulating the thermal conditions of martensite formation on railway wheel treads. In Proceedings of the Second International Conference on Railway Technology: Research, Development and Maintenance, Civil-Comp Press, Stirilingshire, Scotland, 2014, pp. 103-113.

10. SÁBitz, L. and Kolonits, F.: Finite element and analytical computation of flash temperature. Civ. Eng., 58, (2014), 267-278.

11. Wu, L., WEN, Z., LI, W., and JIN, X.: Thermo-elastic-plastic finite element analysis of wheel/rail sliding contact. In Proceedings of the 8th International Conference on Contact Mechanics and Wear of Rail/Wheel Systems, Florence, 2011, pp. 437-443.

12. SÁbitz, L. and Zobory, I.: Finite element modelling of the thermoelastic processes in tread-braked wheels, Conference on Railway Bogies and Running Gears, Budapest, Hungary, 2010. pp. 103-113.

13. Peng, D., Jones, R., and Constable, T.: A study into crack growth in a railway wheel under thermal stop brake loading spectrum. Eng. Fail. Anal., 25, (2012), 280-290.

14. Peng, D., Jones, R., and Constable, T.: An investigation of the influence of rail chill on crack growth in a railway wheel due to braking loads. Eng. Fract. Mech., 98, (2012), $1-14$.

15. Makino, T., Kato, T., and Hirakawa, K.: The effect of slip ratio on the rolling contact fatigue property of railway wheel steel. Int. J. Fatigue, 36, (2012), 68-79.

16. KABO, K.: Material defects in rolling contact fatigue - influence of overloads and defect clusters. Int. J. Fatigue, 24, (2002), 887-894.

17. Ringsberg, J. W. and LindBäck, T.: Rolling contact fatigue analysis of rails including numerical simulations of the rail manufacturing process and repeated wheel-rail contact loads. Int. J. Fatigue, 25, (2003), 547-558.

18. Pletz, M., Daves, W., Yao, W., Kubin, W., and Scheriau, S.: Multi-scale finite element modelling to describe rolling contact fatigue in a wheel-rail test rig. Tribol. Int., 80, (2014), 147-155.

19. Handa, K., Kimura, Y., and Mishima, Y.: Surface cracks initiation on carbon steel railway wheels under concurrent load of continuous rolling contact and cyclic frictional heat. Wear, 268, (2010), 50-58.

20. Handa, K. and Morimoto, F.: Influence of wheel/rail tangential traction force on thermal cracking of railway wheels. Wear, 289, (2012), 112-118.

21. ZwierczyK, P. T. and VÁrAdi, K.: Frictional contact fe analysis in a railway wheel-rail contact. Periodica Polytechnica Mech. Eng., 58, (2014), 93-99.

22. Zwierczyk, P. T. and VÁradi, K.: Thermal stress analysis of a railway wheel in sliding-rolling motion. J. Tribol, 136, (2014), 031401-1-031401-8. 
23. ZWIERCZYK, P. T. and VÁRAdi, K.: Thermal analysis of a railway wheel-rail connection in sliding/rolling motion. The Tenth International Symposium on Tools and Methods of Competitive Engineering (TMCE 2014), Budapest, Hungary, 2014, pp. 1405-1412.

24. Zwierczyk, P. T.: Thermal and stress analysis of a railway wheel rail rolling sliding contact. Ph.D. thesis, Budapest University of Technology and Economics, 2015. 